\title{
PROSES KOMUNIKASI VERBAL PEREMPUAN INDONESIA DI AUSTRALIA
}

(Studi Deskriptif Kualitatif tentang Komunikasi Verbal Perempuan Indonesia dalam Perkumpulan di Australia)

\author{
Sri Seti Indriani, Ditha Prasanti
}

Fakultas Ilmu Komunikasi, Universitas Padjadjaran

Email: rahadianindri@gmail.com, dithaprasanti@gmail.com

\begin{abstract}
Abstrak
Indonesian women that live in Australia have a different way in the verbal communication process than the citizens in Australia. They also are involved in many activities related to the culture tradition of Indonesia, like going to 'asrisan' or 'pengajian' group activities. Looking back on the background culture on where they live which is Australia, they tend to make new cultures. The research focused on how is the verbal communication process that applies within these Indonesian women in activity groups in Australia? The study uses a qualitative approach with a descriptive method. The data collecting technique used are depth interview, documentation study and observation. The result shows that the verbal communication that applies within the Indonesian women in activities group in Australia includes: (1) A new pattern of communication among the Indonesian women. (2) Topics discussed among them are Indonesia food; problems that occur in Indonesia and gossiping about other people.
\end{abstract}

Keywords: Verbal Communication, Indonesian Women, Australia

\section{PENDAHULLUAN}

Komunikasi verbal merupakan hal yang tidak dapat dipisahkan lagi dalam proses interaksi sosial dalam kehidupan sehari-hari. Begitupun halnya jika kita berbicara tentang hubungan atara budaya dan komunikasi memiliki hubungan yang saling berkaitan satu dengan lainnya, tidak dapat dipisahkan karena keduanya saling mempengaruhi. Simbol, bahasa, atau pesan verbal adalah semua jenis simbol yang menggunakan satu kata atau lebih. Bahasa dapat juga dianggap sebagai sistem kode verbal (Mulyana, Deddy, 2010: 69). Bahasa dapat didefinisikan sebagai seperangkat simbol, dengan aturan untuk mengkombinasikan simbol-simbol tersebut, yang digunakan dan dipahami suatu komunitas.

Jalaluddin Rakhmat (2009: 68), mendefinisikan bahasa secara fungsional dan formal. Secara fungsional, bahasa diartikan sebagai alat yang dimiliki bersama untuk mengungkapkan gagasan. Ia menekankan dimiliki bersama, karena bahasa hanya dapat dipahami bila ada kesepakatan di antara anggota-anggota kelompok sosial untuk menggunakannya.

Jadi, bahasa verbal adalah sarana utama untuk menyatakan pikiran, perasaan, dan maksud kita.

Bahasa verbal juga menggunakan kata-kata yang merepresentasikan berbagai aspek realitas individual kita. Dan konsekuensinya, kata-kata adalah abstraksi realitas kita yang tidak mampu menimbulkan reaksi yang merupakan totalitas objek atau konsep yang diwakili kata-kata itu. (Mulyana, Deddy, 2010: 75)

Perempuan Indonesia yang menikah dan tinggal di Australia, seringkali mengadakan berbagai perkumpulan, ini diperuntukkan untuk meningkatkan silahturahmi antara sesama perempuan Indonesia. Tidak jarang alasan mereka adalah untuk mencari kenyamanan, karena mereka 
yang tinggal di luar negeri terkadang mencari identitas diri, identitas tersebut tentu didukung oleh lingkungan sekitar, sehingga perempuan-perempuan tersebut yang berasal dari Indonesia, cenderung mencari perkumpulan yang sama-sama berasal dari negara mereka sendiri. Mereka akan merasa aman tentram karena berada dalam save zone mereka.

Perkumpulan ini ada berbagai macamnya, mulai dari komunitas Indonesia yangmana mereka berkumpul dan membuat sebuat organisasi agar dapat menyelenggarakan berbagai kegiata yang bernuansa Indonesia, contohnya ketika akan merayakan kemerdekaan Indonesia, merayakan hari lebaran bersama, dan kegiatan-kegiatan lainnya yang menonjolkan kekhasan Indonesia. Selain komunitas Indonesia yang beranggota banyak, adapun perkumpulan yang memiliki anggota yang lebih kecil, seperti kelompok yang dibangun berdasarka kesepakatan untuk melakukan arisan.

Berdasarkan latar belakang di atas, peneliti tertarik untuk mengangkat penelitian tentang Komunikasi Verbal Perempuan Indonesia dalam Perkumpulan di Australia. Percampuran budaya yang ada dalam diri perempuan Indonesia tersebut juga akan membuat proses komunikasi verbal ini menjadi menarik untuk diteliti. Oleh karena itu, peneliti semakin tertarik untuk meneliti hal tersebut.

\section{KAJIAN LITERATUR \\ Komunikasi Verbal}

Komunikasi verbal ternyata tidak semudah yang kita bayangkan. Simbol atau pesan verbal adalah semua jenis simbol yang menggunakan satu kata atau lebih. Hampir semua rangsangan bicara yang kita sadari termasuk ke dalam kategori pesan verbal disengaja, yaitu usaha-usaha yang dilakukan secara sadar untuk berhubungan dengan orang lain secara lisan.Suatu sistem kode verbal disebut bahasa. Bahasa juga dapat didefinisikan sebagai seperangkat simbol, dengan aturan untuk mengkombinasikan simbol-simbol tersebut, yang digunakan dan dipahami suatu komunitas.

Secara formal, bahasa diartikan sebagai semua kalimat yang terbayangkan, yang dapat dibuat menurut peraturan tata bahasa. Setiap bahasa mempunyai peraturan bagaimana kata-kata harus disusun dan dirangkaikan supaya memberi arti.

Tatabahasa meliputi tiga unsur: fonologi, sintaksis, dan semantik. Fonologi merupakan pengetahuan tentang bunyi-bunyi dalam bahasa. Sintaksis merupakan pengetahuan tentang cara pembentukan kalimat.

Semantik merupakan pengetahuan tentang arti kata atau gabungan katakata.Menurut Larry L. Barker (dalam Deddy Mulyana,2010: 81), bahasa mempunyai tiga fungsi: penamaan (naming atau labeling), interaksi, dan transmisi informasi.

Penamaan atau penjulukan merujuk pada usaha mengidentifikasikan objek, tindakan, atau orang dengan menyebut namanya sehingga dapat dirujuk dalam komunikasi.

Fungsi interaksi menekankan berbagi gagasan dan emosi, yang dapat mengundang simpati dan pengertian atau kemarahan dan kebingungan. Melalui bahasa, informasi dapat disampaikan kepada orang lain, inilah yang disebut fungsi transmisi dari bahasa. Keistimewaan bahasa sebagai fungsi transmisi informasi yang lintas-waktu, dengan menghubungkan masa lalu, masa kini, dan masa depan, memungkinkan kesinambungan budaya dan tradisi kita.

Cansandra L. Book (1980), dalam Human Communication: Principles, Contexts, and Skills, mengemukakan agar komunikasi kita berhasil, setidaknya bahasa harus memenuhi tiga fungsi, yaitu:

Mengenal dunia di sekitar kita. Melalui bahasa kita mempelajari apa saja yang menarik minat kita, mulai dari sejarah suatu bangsa yang hidup pada masa lalu sampai pada kemajuan teknologi saat ini. 
Berhubungan dengan orang lain. Bahasa memungkinkan kita bergaul dengan orang lain untuk kesenangan kita, dan atau mempengaruhi mereka untuk mencapai tujuan kita. Melalui bahasa kita dapat mengendalikan lingkungan kita, termasuk orang-orang di sekitar kita.

$\begin{array}{rrr}\text { Untuk menciptakan } & \text { koherensi } \\ \text { dalam } \quad \text { kehidupan } & \text { kita. } & \text { Bahasa }\end{array}$ memungkinkan kita untuk lebih teratur, saling memahami mengenal diri kita, kepercayaankepercayaan kita, dan tujuan-tujuan kita (Mulyana, Deddy, 2010: 82)

Makna bahasa dapat pula digolongkan ke dalam makna denotatif dan konotatif. Makna denotatif adalah makna yang sebenarnya (faktual), seperti yang kita temukan dalam kamus dan diterima secara umum oleh kebanyakan orang dengan bahasa dan kebudayaan yang sama. Makna konotatif adalah makna yang subyektif, mengandung penilaian tertentu atau emosional (Onong Effendy, 2004: 12)

\section{METODE PENELITIAN}

Metode penelitian yang digunakan adalah metode kualitatif. "Metodologi adalah proses, prinsip, dan prosedur yang kita gunakan untuk mendekati problem dan mencari jawaban" (Mulyana, 2008: 145). Menurut Sugiyono (2007: 1), metode penelitian kualitatif merupakan suatu penelitian yang digunakan untuk meneliti pada objek yang alamiah dimana peneliti adalah sebagai instrumen kunci, teknik pengumpulan data dilakukan secara gabungan, analisis data bersifat induktif, dan hasil penelitian kualitatif lebih menekankan makna daripada generalisasi. Penelitian kualitatif bertujuan mempertahankan bentuk dan isi perilaku manusia dan menganalisis kualitas-kualitasnya, alih-alih mengubahnya menjadi entitas-entitas kuantitatif (Mulyana, 2008: 150).

Metode yang digunakan peneliti dalam penelitian ini adalah dengan menggunakan metode penelitian deskriptif dengan analisis data kualitatif. Disebut sebagai metode deskriptif karena penelitian ini tidak menggunakan hipotesis dan variabel melainkan hanya menggambarkan dan menganalisis kejadian yang ada tanpa perlakuan khusus atas objek-objek yang diteliti.

Teknik pengumpulan data dalam penelitian kualitatif adalah dengan melakukan observasi, wawancara mendalam, dan studi dokumentasi.

1. Observasi

2. Wawancara

3. Studi Dokumentasi

\section{Informan Penelitian}

Dalam penelitian ini, peneliti menggunakan teknik purposive sampling, yakni dengan mengambil informan sesuai dengan kebutuhan peneliti. Dalam hal ini, peneliti mengambil informan perempuan Indonesia yang aktif mengikuti perkumpulan Arisan dan Pengajian di Brisbane, Australia. Peneliti mengambil 4 orang informan:

1. Linda, asal Jakarta, 30 tahun

2. Puspa, asal Sulawesi, 35 tahun

3. Sri, asal Jakarta, 52 tahun

4. Endang, asal Bogor, 57 tahun

5. Syam, asal Kalimantan, 45 tahun

\section{HASIL DAN PEMBAHASAN}

Dalam penelitian ini, peneliti fokus pada komunikasi verbal yang dilakukan perempuan-perempuan Indonesia ini ketika mereka sedang berkumpul. Ketika mereka sedang arisan dan ketika mereka berbincangbincang ketika kegiatan membaca al-Quran telah selesai.Kami mendatangi dua perkumpulan pengajian pada saat melakukan pengamatan di Brisbane Australia, kedua pengajian tersebut berbeda satu dengan lainnya.

Kelompok pengajian pertama berada pada area South Brisbane, dimana perempuan Indonesia yang berkumpul adalah mereka yang tinggal di daerah selatan Brisbane, dan pengajian satu lagi berada di North Brisbane., mereka yang tinggal di daerah utara Brisbane. Penulis juga melakukan 
pengamatan pada suatu kelompok arisan yang berpusat pada daerah Caboolture dan sekitarnya. Pengajian rutin perempuan Indonesia ini dilakukan pada hari-hari biasa, kelompok pengajian pertama diselenggarakan pada hari selasa, dan yang kedua pada hari jumat. Waktunya dimulai dari jam 10 pagi hingga makan siang. Ini disebabkan untuk mengisi waktu mereka menunggu anak-anak mereka yang sedang sekolah, dan suami yang sdang bekerja. Sedangkan arisan yang dilakukan sebulan sekali ini biasanya diselenggarakan pada hari minggu agar suami dan anak-anak bisa ikut bergabung.

\section{Komunikasi Verbal Perempuan Indonesia dalam perkumpulan pengajian di Australia}

Berdasarkan hasil pengamatan, peneliti dapat menarik beberapa poin yang mereka bicarakan. Dalam hal ini komunikasi verbal mereka ketika mereka sedang berbincang-bincang disela pengajian dan arisan, meskipun pada perkumpulan arisan, perempuan Indonesia ini tidak memilik kebebasan dalam berbicara karena membawa keluarganya. Namun, pada sela sela tertentu ketika mereka berada pada lingkup perempuan mereka dapat berkomunikasi verbal lebih bebas antar sesama. Berikut adalah beberapa hal mengenai proses komunikasi verbal yang mereka lakukan:

1. Kata-kata bersifat ambigu dan kontekstual. Kata-kata bersifat ambigu, karena kata-kata merepresentasikan persepsi dan interpretasi orang-orang yang berbeda, yang menganut latar belakang sosial budaya yang berbeda pula. Kata berat, yang mempunyai makna yang nuansanya beraneka ragam. Misalnya: terdapat dalam penelitian ini berupa kutipan wawancara dalam proses komunikasi verbal yang terjadi dalam beberapa topik pembicaraan.

2. Kata-kata mengandung bias budaya. Bahasa terikat konteks budaya. Oleh karena di dunia ini terdapat berbagai kelompok manusia dengan budaya dan sub-budaya yang berbeda, tidak mengherankan bila terdapat kata-kata yang (kebetulan) sama atau hampir sama tetapi dimaknai secara berbeda, atau kata-kata yang berbeda namun dimaknai secara sama. Konsekuensinya, dua orang yang berasal dari budaya yang berbeda boleh jadi mengalami kesalahpahaman ketika mereka menggunakan kata yang sama.

3. Percampuradukkan fakta, penafsiran, dan penilaian. Dalam berbahasa kita sering mencampuradukkan fakta (uraian), penafsiran (dugaan), dan penilaian. Masalah ini berkaitan dengan dengan kekeliruan persepsi. Contohnya terdapat dalam proses komunikasi verbal di bawah ini.

\section{Proses komunikasi verbal yang terjadi dalam beberapa topik pembicaraan:}

Terbentuknya paralinguistik/ pola bahasa yang baru bagi perempuan Indonesia. Perempuan Indonesia yang berkumpul dalam perkumpulan pengajian dan arisan ini tanpa disadari memiliki pembentukan pola bahasa yang baru, yang disepakati antar sesama perempuan Indonesia tersebut.

Hal ini tercermin misalnya dalam komunikasi verbal memilih makanan dan masakan. Mereka mengalami kesulitan dalam mencari bumbu-bumbu masakan Indonesia di Australia, meskipun ada toko-toko yang menyediakannya namun tempatnya jauh, membuat mereka bereksperimen dalam membuat berbagai masakan Indonesia dengan bumbu-bumbu yang ada. Kadang mereka membicarakan proses pembuatannya dan bagaimana mereka mendapatkan bumbu tersebut. Pada satu sesi pertemuan pengajian di south Brisbane, Linda membicarakan daun bayam yang ia tekankan bahwa bayam yang ada di Indonesia dan Australia memiliki rasa yang lain. Puspa setuju dengan hal itu, sehingga masakan jadi yang berisi bayam tentu akan terasa beda ketika masak di 
Indonesia dengan masak di Australia. Pada waktu yang lain, Sri dan Endang membicarakan bubur sagu yang dibuat oleh Sri dan memuji olahan santannya.

Terkadang masakan yang dibawa sebagai budaya potluck ini mendapat pujian, namun, seringkali sebaliknya, digossipkan di belakang seperti yang dialami oleh Syam, ia mengurangi waktunya dalam ikut berkumpul dengan perempuan-perempuan Indonesia alasannya karena sakit hati dia digossipkan di belakang.

'saya tidak mau lagi
berkumpul, karena mereka bilang
masakan saya tidak enak, saya sakit
hati'.

\section{Pembicaraan seputar Indonesia}

Tidak jarang mereka membicarakan Indonesia, negara asal mereka. Meskipun yang mereka bicarakan kebanyakan hal-hal yang bersifat negatif, namun mereka tetap mengakui akan cintanya mereka pada tanah air. Pembicaraan mereka mengenai Indonesia seputar hal-hal yang 'menggangu' mereka, apalagi bila ada salah satu peserta kelompok tersebut yang baru saja pulang dari Indonesia. Mereka akan bercerita bagaimana tidak teraturnya Indonesia, seperti mengenai kemacetan, polusi, masakan tidak sehat dan lainnya. Lia, salah satu perempuan Indonesia mengakui bahwa setibanya dia di Indonesia dia merasa bahwa dia menjadi pribadi yang berbeda, yaitupribadi yang selalu mengeluh dan emosinya semakin tinggi. Sehingga dia ingin segera kembali pulang ke Australia.

Lia juga membicarakan masalah buang sampah yang dilakukan orang-orang Indonesia di Jakarta yangmana masih banyak orang tidak bertanggung jawab dan membuang sampah sembarangan. "Subhanalloh, saya kayaknya kalo di Jakarta buat pelajaran banget-banget deh, jadi udah males lama tinggal disana..stress, orangorangnya gak sabaran.. yah saya jadi ikutikutan emosian.."

\section{Membicarakan orang lain alias Gossip}

Pada satu sesi perkumpulan arisan ketika para perempuan sedang berkumpul, dua perempuan Indonesia asik membicarakan mbak Puspa yang orang Indonesia dan baru saja cerai dengan suaminya yang berwarga negara Australia. Mereka menyayangkan perceraia tersebut, padahal menurut mereka mantan suami dari Puspa adalah orang yang baik dan tanggung jawab, alasan mbak puspa sendiri menuut mereka adalah masalah agama, karena mbak Puspa menginginkan seorang iman sesuai dengan apa yang dianjurkan dalam agama islam. Namun, dibalik itu semua menurut mereka, Puspa tidak masak akal, karena Puspa sendiri masih kurang islami dan masih sering ke pub malam.

Pada beberapa kali, penulis ketika melakukan pengamatan, ia melihat bahwa ada yang mencibir ketika seseorang yang hanya membawa makanan kaleng (yang tidak dimasak), akibat itu, orang tersebut akan dijadikan bahan omongan untuk beberapa minggu kedepan. Peneliti pun mengamati bahwa para senior (perempuan Indonesia yang telah lama ikut perkumpulan) ketika mencicipi sebuah masakan yang dibawa oleh salah satu peserta, akan mengatakan "ah tidak enak" atau "enak'. Jika masakan yang mereka cicipi tidak enak, itupun akan menjadi masalah yang akan dibincangkan oleh mereka untuk beberapa minggu kedepan.

\section{Analisis Teori Interaksi Simbolik}

Berdasarkan pemaparan tentang latar belakang pemikiran besar tentang manusia yang mempengaruhi pemikiran George Herbert Mead dan konsep dasar dari interaksi simbolik, maka dapat disimpukan bahwa terdapat tiga tema konsep interaksi simbolik (West \& Turner: 2007), yaitu :

1. Pentingnya makna bagi perilaku manusia, hal ini relevan dengan penelitian yang dilakukan peneliti yakni pentingnya makna save zone bagi perempuan Indonesia yang 
bergabung dalam perkumpulan pengajian dan arisan di Australia. Mereka yang berada dalam perkumpulan pengajian dan arisan tersebut merasa ada dalam save zone.

2. Pentingnya konsep mengenai diri, hal ini relevan dengan penelitian ini bahwa perempuan Indonesia yang berkumpul tersebut menyatakan pentingnya konsep mengenai diri mereka. Ketika mereka saling memberikan penilaian satu sama lain, mereka saling mengomentari diri masing-masing. Begitupun halnya terjadi setiap kali mereka melakukan perkumpulan pengajian dan arisan.

3. Hubungan antara individu dengan masyarakat, hal ini pun relevan dengan penelitian ini bahwa hubungan antara perempuan Indonesia yang tinggal di Australia dengan masyarakat yang ada di sana memiliki perbedaan besar. Dalam hal ini, interaksi tersebut akan saling mempengaruhi, bagaimana pola pikirnya, makna yang disepakati bersama antara individu dan masyarakat.

Aktivitas individu yakni perempuan Indonesia dalam menggunakan simbol atau bahasa dilakukannya melalui interaksi dengan masyarakat. Hasil aktivitas perempuan Indonesia ini akan berpengaruh pada masyarakat tempat individu tersebut berinteraksi. Hubungan antara masyarakat dan individu yang berinterkasi menggunakan simbol-simbol yang sama, akan mereka maknai sesuai dengan interaksi mereka tersebut. Interaksi menggunakan simbol yang sama dalam suatu masyarakat ini dapat membentuk konstruksi realitas sosial bagi individu yang terlibat di dalamnya. Hal ini tercermin dalam komunikasi verbal yang terjadi saat perempuan Indonesia berada dalam perkumpulan di Australia.

\section{KESIMPULAN}

Berdasarkan hasil pembahasan yang tertulis diatas, maka peneliti dapat membuat beberapa kesimpulan yang menarik seperti di bawah ini:

Komunikasi verbal yang terjadi ketika perempuan Indonesia ini sedang berkumpul adalah terbentuknya pola bahasa/ paralinguistik yang baru di antara sesama perempuan Indonesia, sedangkan topik pembicaraan yang umumnya mereka komunikasikan adalah mengenai: makanan dan masakan Indonesia; masalah yang ada di Indonesia; dan menggosipkan orang lain.

\section{Saran}

Berdasarkan penelitian yang dilakukan, sebaiknya perempuan Indonesia yang tinggal di Australia melakukan program/ kegiatan yang membangun nasionalisme Indonesia supaya tidak muncul proses komunikasi verbal yang mengarah kepada pembicaraan yang negatif.

\section{DAFTAR PUSTAKA}

Bungin, Burhan. 2007. Penelitian Kualitatif. Jakarta: Kencana Prenada Media Group

Effendy, Onong Uchjana. 2004. Ilmu Teori dan Filsafat Komunikasi. Bandung: Citra Aditya Bakti.

Mulyana, Deddy. 2010. Pengantar Ilmu Komunikasi. Bandung: PT Remaja

Rosdakarya. 2008. Metode

Penelitian Komunikasi. Bandung: PT Remaja Rosdakarya

Rakhmat, Jalaludin. 2009. Metode

Penelitian Komunikasi. Bandung : PT

Remaja Rosdakarya.

Komunikasi. Bandung : PT Remaja

Rosdakarya.

Sugiyono. 2007. Metode Penelitian Kuantitatif, Kuantitatif dan $R \& D$. Bandung: Alfabeta.

West, Richard. Lynn H.Turner. 2007. "Pengantar Teori Komunikasi". Jakarta:

Salemba Human 